\title{
Clinical Status of Patients with Cerebrospinal Fluid Hypovolemia Treated with an Epidural Blood Patch
}

\author{
Takafumi Nishizaki, Norio Ikeda, Shigeki Nakano, Takanori Sakakura, Natsumi Fujii, \\ Tomomi Okamura \\ Ube Industries Central Hospital, Ube, Japan \\ Email: nishiza@jeans.ocn.ne.jp
}

Received 19 July 2015; accepted 9 October 2015; published 12 October 2015

Copyright (C) 2015 by authors and Scientific Research Publishing Inc.

This work is licensed under the Creative Commons Attribution International License (CC BY). http://creativecommons.org/licenses/by/4.0/

c) $\underset{\mathrm{EY}}{\mathrm{C}}$ Open Access

\section{Abstract}

Objective: Use of an epidural self-blood patch (EBP) is the most effective form of therapy for patients with cerebrospinal fluid (CSF) hypovolemia. However, even if the symptoms are resolved, other clinical aspects of this condition frequently prevent patients resuming social activity. In the present study, we investigated the clinical course of patients with CSF hypovolemia after treatment with an EBP to assess the factors affecting return to work or school, and considered the treatment of patients with progressive chronic subdural hematoma. Patients and Results: We investigated a group of 10 patients with CSF hypovolemia. After initial application of an EBP, 8 of these patients were completely relieved of postural headache and associated symptoms, and the other 2 recovered after a second application. However, 3 patients who had cervical spondylosis or psychosis were still unable to return to work or school. Two patients who were forced to retire have potential for rehabilitation after EBP. One patient has recovered from the illness, but could not return to school due to persistent medical history of psychosis. These patients had suffered symptoms for a long period before EBP (mean, 17.8 months; range 7 months to 3 years) relative to those who were able to resume social activity (mean, 2.0 months; range 7 days to 5 months) $(\mathrm{P}<$ 0.05). Three had progressive bilateral chronic subdural hematoma. One of these patients required emergency burr-hole drainage to resolve the neurological deterioration. Conclusions: Both physicians and patients need to be aware of CSF hypovolemia, and the fact that it requires appropriate treatment without delay. While application of an EBP is a fundamentally important therapy even for patients with hematoma, careful follow-up is required for patients showing marked neurological deterioration or an increasing hematoma volume with a brain midline shift, and burr-hole drainage must sometimes be considered in combination with EBP. 
Keywords

CSF Hypovolemia, Epidural Self-Blood Patch, Chronic Subdural Hematoma

\section{Introduction}

Cerebrospinal fluid (CSF) hypovolemia is a recently well recognized cause of persistent and postural headaches induced by spinal CSF leakage [1]-[4]. Pachymeningeal enhancement and downward displacement of the brain on MRI are the characteristic radiological features of this condition [5]. Initial therapy is drip infusion and bed rest for several weeks. For patients who do not respond to this treatment, application of an epidural self-blood patch (EBP) is the most effective therapy [2] [6] [7]. Even if the symptoms are resolved, other clinical aspects of this condition frequently prevent patients from resuming social activity. We recently used EBP to treat 10 patients with CSF hypovolemia during a two-year period at a single institution. In the present study, we investigated the clinical course of these patients after EBP application to clarify the factors affecting return to work or school. Three of the studied patients who had progressive chronic subdural hematoma showed exacerbation of symptoms, and we further considered the optimal treatment for such patients.

\section{Patients/Materials and Methods}

We studied 10 consecutive patients with CSF hypovolemia who had been referred to our institution for examination and treatment between August 2009 and July 2011 (Table 1). In all of the patients, the symptoms had not been resolved by at least one week of bed rest before application of an EBP. The patients comprised 4 men and 6 women with a mean age of 35 years (range 14 - 51 years). All of them had suffered postural headaches over periods ranging from 1 week to 3 years. Gd-enhanced MR imaging was performed in all cases (Figure 1), and the presence of CSF leakage was additionally confirmed by RI scintigraphy (3 cases) (Figure 2) and MR myelography (1 case). EBP application with self-blood was performed a total of 12 times at the cervical (1 case), thoracic ( 1 case) and lumbar levels (10 cases) in these 10 patients. The mean follow-up period from the time of the last treatment was 16 months (range 6 - 28 months). The clinical status of these patients was evaluated in terms of symptom relief and ability to return to work or school. Karnofsky performance status (KPS) prior and after the final treatment, was used as a quantified outcome parameter [8]. Mean values were analyzed using unpaired t-test. Differences at a $\mathrm{p}<0.05$ were considered to be statistically significant.

\section{Results}

Eight of the 10 patients obtained complete relief from postural headache and other symptoms associated with CSF hypovolemia after the initial EBP treatment. One patient (case 5) initially recovered after EBT, but the symptoms recurred when he suffered an accidental fall onto his coccygeal region 3 months after the treatment. After receiving EBP again, he recovered and returned to work. In another patient (case 6) who failed to respond to the initial EBP performed at the L2/3 level, additional RI scintigraphy demonstrated CSF leakage at the cervical level. Four weeks later, he received an EBP at the C6/7 level, and the symptoms of postural headache were completely resolved. KPS prior and after the final treatment ranged from 50 to 70 (mean: 63) and 80 to 100 (mean: 95), respectively (Table 1). Thus, EBP was finally effective in all patients. However, 3 of the 10 patients were unable to return to work or school during follow-up periods ranging from 6 to 19 months. Two patients who had been forced to retire, had enough potential for rehabilitation after EBP. Another young patient could not return to school due to persistent medical history of psychosis. These 3 patients had suffered symptoms for a long period before EBP (mean, 17.8 months; range 7 months to 3 years) relative to those who had been able to return to work or school (mean, 2.0 months; range 7 days to 5 months) $(\mathrm{p}<0.05)$.

Threee patients (cases 8, 9 and 10) had bilateral chronic subdural hematoma without obvious traumatic episodes. All of them had been initially treated conservatively, but their symptoms had worsened. MRI or CT scan revealed apparent enlargement of the hematoma. In one patient (case 8) who had developed postural headache one month before, MRI revealed bilateral chronic subdural hematoma and pachymeningeal enhancement. Under a diagnosis of CSF hypovolemia, he received drip infusion and bed rest for 2 weeks, but the symptoms worsened 
Table 1. Patients with cerebrospinal fluid hypovolemia treated with an epidural blood patch.

\begin{tabular}{|c|c|c|c|c|c|c|c|c|c|}
\hline Case & $\begin{array}{l}\text { Age } \\
\text { gender }\end{array}$ & Symptoms & KPS & $\begin{array}{l}\text { Duration of } \\
\text { symptoms }\end{array}$ & $\mathrm{CSDH}$ & $\begin{array}{c}\text { EBP } \\
\text { (injection } \\
\text { level) }\end{array}$ & $\begin{array}{l}\text { KPS at } \\
\text { discharge }\end{array}$ & $\begin{array}{l}\text { Follow-up } \\
\text { months }\end{array}$ & $\begin{array}{c}\text { Return to } \\
\text { work or } \\
\text { school }\end{array}$ \\
\hline 1) & $24 \mathrm{~F}$ & Headache, nausea & 60 & 1 week & None & $\mathrm{L} 1 / 2$ & 100 & 10 & Yes \\
\hline 2) & $14 \mathrm{~F}$ & Headache & 70 & 6 weeks & None & $\mathrm{L} 1 / 2$ & 100 & 24 & Yes \\
\hline 3) & $16 \mathrm{~F}$ & Headache, nausea & 50 & 1 year & None & $\mathrm{L} 1 / 2$ & 80 & 6 & No (psychosis) \\
\hline 4) & $41 \mathrm{~F}$ & $\begin{array}{c}\text { Headache, nausea, numbness, sleep } \\
\text { disturbance, dizziness }\end{array}$ & 70 & 7 months & None & $\mathrm{L} 3 / 4$ & 90 & 19 & $\begin{array}{l}\text { No (potential } \\
\text { rehabilitation) }\end{array}$ \\
\hline 5) & $37 \mathrm{M}$ & $\begin{array}{l}\text { Headache, floating sensation, tremor, } \\
\text { double vision, motor weakness }\end{array}$ & 60 & 5 months & None & L2/3, L2/3 & 90 & 12 & Yes \\
\hline 6) & $45 \mathrm{M}$ & $\begin{array}{l}\text { Headache, appetite loss, dizziness, } \\
\text { numbness, gait disturbance }\end{array}$ & 70 & 3 years & None & $\begin{array}{l}\mathrm{L} 2 / 3 \\
\mathrm{C} 6 / 7\end{array}$ & 90 & 14 & $\begin{array}{l}\text { No (potential } \\
\text { rehabilitation) }\end{array}$ \\
\hline 7) & $47 \mathrm{M}$ & Headache, nausea, vertigo, appetite loss & 60 & 2 weeks & None & $\mathrm{L} 1 / 2$ & 100 & 28 & Yes \\
\hline 8) & 38M & Headache, vomiting, dizziness & 60 & 5 weeks & Yes & Th6/7 & 100 & 12 & Yes \\
\hline 9) & 39M & Headache, left abducens palsy & 60 & 3 weeks & $\begin{array}{c}\text { Yes } \\
\text { (evacuation) }\end{array}$ & $\mathrm{L} 1 / 2$ & 100 & 15 & Yes \\
\hline 10) & $51 \mathrm{M}$ & Headache, disorientation & 70 & 3 months & $\begin{array}{c}\text { Yes } \\
\text { (evacuation) }\end{array}$ & $\mathrm{L} 3 / 4$ & 100 & 20 & Yes \\
\hline
\end{tabular}

KPS: Karnofsky performance status.

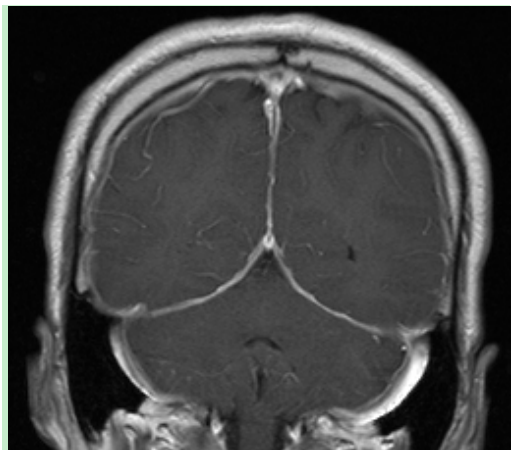

(a)

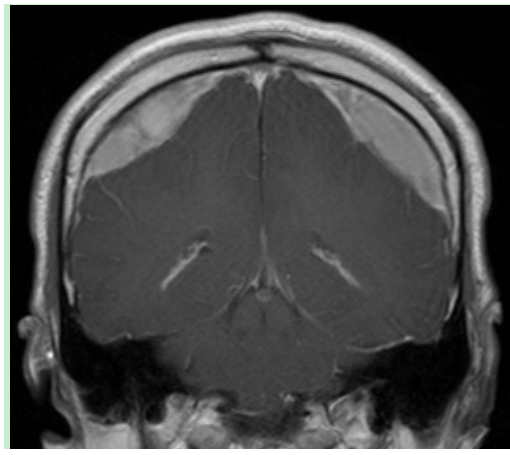

(b)

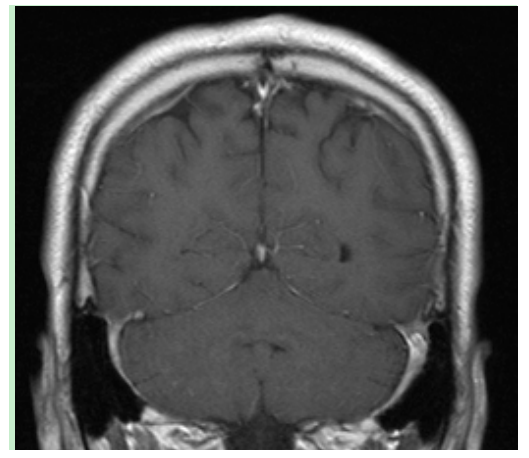

(c)

Figure 1. Case 9: MRI demonstrates pachymeningeal enhancement before EBP (a); One month after successful EBP, this patient suffered neurological deterioration, and MRI revealed bilateral chronic subdural hematoma with a marked mass effect (b); Three months after evacuation of the hematoma, MRI demonstrated neither pachymeningeal enhancement nor hematoma (c).

and MRI revealed enlargement of the hematoma. As MR myelography revealed CSF leakage at the Th 5 - 7 levels, he underwent EBP placement at the Th 6/7 level, resulting in immediate relief of the symptoms and disappearance of the hematoma. Another patient (case 9) who had suffered from postural headache and left abducens palsy (Figure 1(a)), was treated successfully with EBP. However, he gradually developed headache and vomiting, and finally became semicomatose one month later. MRI revealed bilateral chronic subdural hematoma with a marked mass effect (Figure 1(b)). After evacuation of the hematoma via bilateral burr-hole drainage, he completely recovered (Figure $\mathbf{1}(\mathrm{c})$ ). The third patient (case 10), who had postural headache and mild disorientation due to bilateral chronic subdural hematoma, was diagnosed as having CSF hypovolemia by MRI. He was initially treated with bed rest, but did not attend for medical examination thereafter. Six weeks later, his headache worsened and he was unable to continue his driving work because of disorientation. CT scan revealed enlargement of the chronic subdural hematoma. Despite evacuation of the hematoma, the postural headache did not 


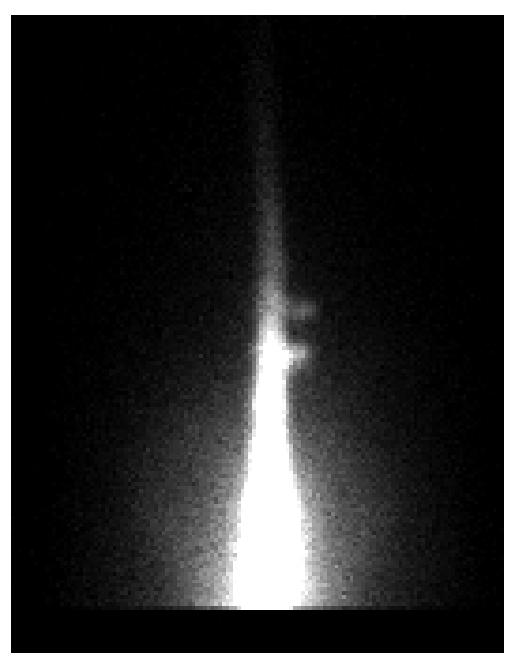

Figure 2. Case 7: Radioisotope cisternography demonstrates leakage of the isotope at the lumbar level, 2 hours after intrathecal injection of Indium-111 radionuclide.

resolve, and persistent air accumulation was demonstrated by CT scan. After application of an EBP 6 days later, the symptoms disappeared, and a follow-up CT scan revealed no subdural hematoma.

\section{Discussion}

Although acquired CSF leaks can be caused by head or spine injury, surgery, infection or tumor, spontaneous leaks are also common. A CSF leak can be identified by radioisotope cisternography and CT myelography in approximately $60 \%$ of cases [8]-[11]. The initial treatment for CSF hypovolemia includes bed rest and intravenous hydration. Epidural blood patch is used in patients with spinal leaks who fail noninvasive measures [2] [6] [7]. Surgical repair is usually used in patients with leaks in the skull. Many authors have reported the effectiveness of EBP placement for patients with CSF hypovolemia, and our present series also suggested that most patients who undergo EBP are relieved of the symptoms associated with this condition. In the present series, the duration of symptoms appeared to be an important factor affecting the ability of patients to return to work or school. This may be due to the fact that other related conditions, such as cervical spondylosis and psychogenic problems, make it difficult to obtain a precise diagnosis of CSF hypovolemia. However, such long-standing symptoms may also give rise to other social problems. Two patients who had been forced to retire, had enough potential for rehabilitation after EBP. If these patients had been treated without delay, they might resume previous social activity. Another young patient could not return to school due to persistent medical history of psychosis. Long-standing symptoms may sometimes worsen psychogenic problems. Even though postural headache is resolved, other conditions such as cervical spondylosis or psychosis themselves may prevent early rehabilitation. We believe that both physicians and patients need to be aware of CSF hypovolemia, so that appropriate treatment can be initiated without delay.

Schievink et al. reported that subdural fluid collection and subacute or chronic subdural hematoma with a significant mass effect were seen in $50 \%$ and $20 \%$ of patients with spontaneous CSF hypovolemia, respectively [12]. Similarly, 30\% of the patients in our present series showed a significant mass effect. Schievink et al. suggested that subdural fluid collection associated with spontaneous CSF hypovolemia, including large subdural hematomas, can be managed by directing the treatment at the underlying CSF leakage without any need for a craniotomy or burr-hole drainage. Two of our patients (cases 8 and 10) with persistent symptoms were subsequently cured by EBP. If the underlying CSF leakage remains untreated, the risk of recurrent SDH becomes high. One of our patients (case 9) showing marked enlargement of chronic subdural hematoma after EBP recovered after simple evacuation of the hematoma. One similar case, in which simple evacuation of the subdural hematoma relieved the symptoms in a patient with progressive and symptomatic hematoma after EBP, has been reported [9] [13]. Mikawa et al. reported another similar case, in which a patient with CSDH with mass effect and a midline shift developed oculomotor nerve palsy 18 hours after EBP [14]. The patient was successfully treated 
with burr-hole drainage alone, similarly to our patient. Hashimoto et al. also reported a similar case in which the patient became comatose due to a large hematoma after application of an EBP [15]. After a second EBP, this patient required burr-hole drainage. The authors speculated that recurrent CSF leakage, or intrathecal injection for pretreatment RI scintigraphy, had caused progressive hematoma by significantly changing the intracranial pressure. However, our patient (case 9), as well as the patient reported by Mikawa, recovered after evacuation of the hematoma without EBP retreatment, and did not undergo any intrathecal examination preoperatively. While we agree that EBP application is the most fundamental and important treatment for patients with hematoma, those showing neurological deterioration, an increasing hematoma volume and a brain midline shift or consciousness disturbance require careful follow-up, and burr-hole drainage should sometimes be considered in conjunction with EBP. The mechanism responsible for growth of a chronic subdural hematoma is generally associated with high coagulability and fibrinolytic activity. We speculate that in this patient, typical chronic subdural hematoma after EBP arose through the same mechanism as that of chronic subdural hematoma in which enlargement of the subdural/subarachnoid space occurred due to loss of CSF, causing tearing of the bridging veins that persisted even after EBP.

\section{Conclusion}

Patients who have long-standing symptoms before EBP have difficulty in resuming social activity. Physicians and patients need to be aware of CSF hypovolemia so that appropriate treatment can be initiated without delay. EBP placement is a fundamental and important treatment even for patients with hematoma. Patients with neurological deterioration, an increasing hematoma volume and a brain midline shift or consciousness disturbance require careful follow-up, and burr-hole drainage should sometimes be considered in conjunction with EBP.

\section{References}

[1] Mokri, B. (1999) Review Spontaneous Cerebrospinal Fluid Leaks: From Intracranial Hypotension to Cerebrospinal Fluid Hypovolemia_Evolution of a Concept. Mayo Clinic Proceedings, 74, 1113-1123. http://dx.doi.org/10.4065/74.11.1113

[2] Chiapparini, L., Ciceri, E., Nappini, S., Castellani, M.R., Mea, E., Bussone, G., Leone, M. and Savoiardo, M. (2004) Headache and Intracranial Hypotension: Neuroradiological Findings. Neurological Sciences, 25, 138-141. http://dx.doi.org/10.1007/s10072-004-0273-9

[3] Ferrante, E., Savino, A., Sances, G. and Nappi, G. (2004) Spontaneous Intracranial Hypotension Syndrome: Report of Twelve Cases. Headache, 44, 615-662. http://dx.doi.org/10.1111/j.1526-4610.2004.446012.x

[4] Mokri, B. (2004) Low Cerebrospinal Fluid Pressure Syndromes. Neurologic Clinics, 22, 55-74. http://dx.doi.org/10.1016/S0733-8619(03)00089-6

[5] Mokri, B., Parisi, J.E., Scheithauer, B.W., Piepgras, D.G. and Miller, G.M. (1995) Meningeal Biopsy in Intracranial Hypotension: Meningeal Enhancement on MRI. Neurology, 45, 1801-1807. http://dx.doi.org/10.1212/WNL.45.10.1801

[6] Berroir, S., Loisel, B., Ducros, A., Boukobza, M., Tzourio, C., Valade, D. and Bousser, M.G. (2004) Early epidural Blood Patch in Spontaneous Intracranial Hypotension. Neurology, 63, 1950-1951. http://dx.doi.org/10.1212/01.WNL.0000144339.34733.E9

[7] Sencakova, D., Mokri, B.R. and McClelland, R.L. (2001) The Efficacy of Epidural Blood Patch in Spontaneous CSF Leaks. Neurology, 57, 1921-1923. http://dx.doi.org/10.1212/WNL.57.10.1921

[8] Schag, C.C., Heinrich, R.L. and Ganz, P.A. (1984) Karnofsky Performance Status Revisited: Reliability, Validity, and Guidelines. Journal of Clinical Oncology, 2, 187-193.

[9] Chung, S.J., Kim, J.S. and Lee, M.C. (2000) Syndrome of Cerebral Spinal Fluid Hypovolemia: Clinical and Imaging Features and Outcome. Neurology, 55, 1321-1327. http://dx.doi.org/10.1212/WNL.55.9.1321

[10] Mokri, B., Piepgras, D.G. and Miller, G.M. (1997) Syndrome of Orthostatic Headaches and Diffuse Pachymeningeal Gadolinium Enhancement. Mayo Clinic Proceedings, 72, 400-413. http://dx.doi.org/10.4065/72.5.400

[11] Yousry, I., Forderreuther, S., Moriggl, B., Holtmannspotter, M., Naidich, T.P., Straube, A. and Yousry, T.A. (2001) Cerebral MR Imaging in Postural Headache: MR Signs and Pathophysiological Implications. AJNR, 22, 1239-1250.

[12] Schievink, W.I., Maya, M.M., Moser, F.G. and Tourje, J. (2005) Spectrum of Subdural Fluid Collections in Spontaneous Intracranial Hypotension. Journal of Neurosurgery, 103, 608-613. http://dx.doi.org/10.3171/jns.2005.103.4.0608

[13] De Noronha, R.J., Sharrack, B., Hadjivassiliou, M. and Romanowski, C.A. (2003) Subdural Haematoma: A Potentially Serious Consequence of Spontaneous Intracranial Hypotension. Journal of Neurology Neurosurgery and Psychiatry, 
74, 752-755. http://dx.doi.org/10.1136/jnnp.74.6.752

[14] Mikawa, S. and Ebina, T. (2001) Spontaneous Intracranial Hypotension Complicating Subdural Hematoma: Unilateral Oculomotor Nerve Palsy Caused by Epidural Blood Patch. No Shinkei Geka, 29, 747-753.

[15] Hashimoto, N., Yamane, K., Okii, N., Ishinokami, S., Onda, H., Touji, H. and Hanaya, R. (2009) A Case of Spontaneous Cerebrospinal Fluid Hypovolemia with Coma and Chronic Subdural Hematoma after Epidural Self-Blood Patch Therapy. Japanese Journal of Neurosurgery, 18, 525-530. 